\title{
Noise Characteristics for Co-Cr-Ta Media and Ferrite Media
}

\author{
Shinzo TSUBOI, Takahiro KORENARI, Nobuyuki ISHIWATA, \\ Kazuhiko YAMADA and Katsumichi TAGAMI
}

\author{
Functional Devices Research Laboratories, NEC Corporation \\ 1-1, Miyazaki 4-Chome, Miyamae-ku, Kawasaki, Kanagawa 216, Japan
}

\begin{abstract}
The effect of the residual magnetic flux density $(\mathrm{Br})$ on the media noise in $\mathrm{Co}-\mathrm{Cr}-\mathrm{Ta}$ alloy thin films has been investigated. Longitudinal media with higher $\mathrm{Br}$ and thinner magnetic layer have superior media noise to signal ratio compared to media with lower $\mathrm{Br}$ (below 2,000 G) and thicker magnetic layer under the constant $\mathrm{Br} \delta$, where $\delta$ is the magnetic layer thickness. It was revealed that media noise is proportional to fluctuations in the magnetic transition region according to analysis of the readback waveform. Furthermore, ferrite media exhibits an excellent possibility for use as a low noise media at high recording densities.
\end{abstract}

\section{INTRODUCTION}

Longitudinal Co-Cr-Ta alloy thin films with $\mathrm{Cr}$ underlayer have been widely used as recording media. In high-density magnetic recording using a magnetoresistive (MR) head, it is important to decrease the media noise as well as to increase the readback signal because of the low MR head impedance noise. Readback waveform analyzing ${ }^{1,2)}$ has revealed that the media noise is connected with fluctuations in the magnetic transition region. The magnetic transition length depends on the magnetic layer thickness $(\delta)$ and magnetic properties such as the coercive force $\left(\mathrm{H}_{c}\right)$ and the residual flux density $(\mathrm{Br})$. Therefore, the media noise also correlates with $\delta, \mathrm{H}_{\mathrm{c}}$ and $\mathrm{Br}$. To adjust the media noise for low MR impedance, the $\operatorname{Br} \delta$ product tends to become smaller. However, the $\mathrm{Br}$ effect on the media noise has not been investigated over a wide range of $\mathrm{Br}$.

In addition to $\mathrm{Co}-\mathrm{Cr}-\mathrm{Ta}$ alloy thin film media, $\gamma-\mathrm{Fe}_{2} \mathrm{O}_{3}$ film media are also known to exhibit low noise for an inductive (ID) head ${ }^{3)}$. In comparison to metal films, sputtered $\gamma-\mathrm{Fe}_{2} \mathrm{O}_{3}$ thin films are more attractive magnetic recording media because of their excellent corrosion and wear resistance. Furthermore, from the point of film microstructure, there is interest in comparing noise characteristics for $\mathrm{Co}-\mathrm{Cr}-\mathrm{Ta}$ media and ferrite media when using an MR head.

This paper reports the noise characteristics for $\mathrm{Co}-\mathrm{Cr}-\mathrm{Ta}$ media and ferrite media at high recording densities.

\section{EXPERIMENTAL METHODS}

Co-Cr-Ta films and magnetite $\left(\mathrm{Fe}_{3} \mathrm{O}_{4}\right)$ films were prepared on glass substrates using the rf sputtering in an argon atmosphere. The substrate temperature was about $200{ }^{\circ} \mathrm{C}$. The base pressure was about $5 \times 10^{-7}$ Torr and Ar sputtering pressure was fixed at $1.7 \mathrm{mTorr}$. The sputtering power density on the targets was fixed at 5.5 $\mathrm{W} / \mathrm{cm}^{2}$. The $\mathrm{Cr}$ content for $\mathrm{Co}-\mathrm{Cr}-\mathrm{Ta}$ was varied between 12 and 18 at\% to control the residual magnetic flux density. The $\mathrm{Cr}$ underlayer was $83 \mathrm{~nm}$ thick and the protection layer was $20 \mathrm{~nm}$ thick. The magnetic layer thickness was varied between 16 and $70 \mathrm{~nm}$, to keep the value of the $\mathrm{Br} \delta$ products constant (110G $\mu \mathrm{m}$ ). Ferrite films, in which $1 \sim 3$ at $\%$ Co and $\mathrm{Cu}$ were doped, were annealed at various temperatures, from $200{ }^{\circ} \mathrm{C}$ to $400{ }^{\circ} \mathrm{C}$, for oxidation. The Co doping element increases the coercive force $\left(\mathrm{H}_{\mathrm{c}}\right)$ and the $\mathrm{Cu}$ element accelerates oxidation of $\mathrm{Fe}_{3} \mathrm{O}_{4}$ into $\gamma-\mathrm{Fe}_{2} \mathrm{O}_{3}{ }^{4}$. In order to evaluate magnetic grain isolation for media films, the $\delta \mathrm{M}$ values were measured using a vibrating sample magnetometer $(\text { VSM })^{5}$. Film structures were analyzed by X-ray diffraction.

Magnetic recording characteristics were measured with a dual-element head consisting of a thin-film inductive write head and an MR read head. The track widths for ID head and MR head were $5 \mu \mathrm{m}$ and $3 \mu \mathrm{m}$, respectively. The gap lengths for $\mathrm{ID}$ head and MR head were about $0.7 \mu \mathrm{m}$ and about $0.5 \mu \mathrm{m}$, respectively. The noise power for longitudinal recording media at high recording densities was correlated to the magnetic transition region shape fluctuation ${ }^{12,6)}$. The fluctuation affects on the half-width values $\left(\mathrm{W}_{1}, \mathrm{~W}_{2}, \mathrm{~W}_{3}, \cdots\right)$ of the readback waveform, as shown in Fig.1. The half widths were measured at ten thousand, using a time interval analyzer, and the average half width value and the standard deviation $(\sigma)$ were calculated. $\sigma$ was defined as the half-width fluctuation $^{2}$.

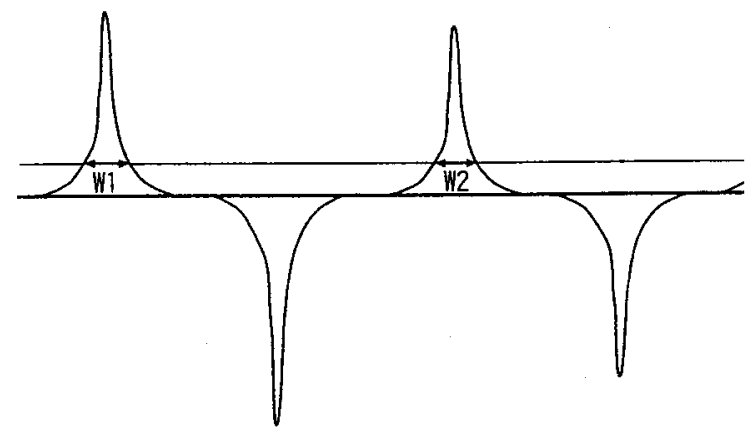

Figure 1 Method for measuring the fluctuation in the half-width of readback waveform at $60 \mathrm{kFRPI}$. 


\section{RESULTS AND DISCUSSION}

\section{A. Dependence on $R / W$ characteristics on the $\mathrm{Br}$ of $\mathrm{Co}$ - Cr-Ta media}

Under a constant $\mathrm{Br} \delta$ condition, the $\mathrm{R} / \mathrm{W}$ characteristics for $\mathrm{Co}-\mathrm{Cr}-\mathrm{Ta}$ media having different $\mathrm{Br}$ values were examined. Table 1 shows values of the residual magnetic flux densities $(\mathrm{Br})$, film thickness $(\delta)$, coercivity $\left(\mathrm{H}_{c}\right)$ and coercivity squareness $\left(\mathrm{S}^{*}\right)$ for individual samples. As shown in the Table, $\mathrm{H}_{c}$ values gradually decrease with a decrease in $\mathrm{Br}$. The change in the $H_{c}$ value is probably caused by change of the grain sizes and the $\mathrm{Cr}$ segregation states due to a difference of the chemical affinity of the atoms. The grain sizes in the lower $\mathrm{Br}$ media would be larger than those for the higher $\mathrm{Br}$ media because the magnetic layer of the former is thicker than that of the latter. Furthermore, the low $\mathrm{Br}$ media with higher $\mathrm{Cr}$ content and thicker magnetic layer has more perpendicular component in the films. This is also one of the reason of the $\mathrm{H}_{\mathrm{c}}$ decline in the low $\mathrm{Br}$ media.

Figure 2 shows the dependence of the isolated readback signal at $4 \mathrm{kFRPI}\left(\mathrm{S}_{0}\right)$ and recording density $\mathrm{D}_{50}$ on $\mathrm{Br}$ for the media samples shown in Table $1 . \mathrm{S}_{0}$ and $\mathrm{D}_{50}$ decrease with a decrease in $\mathrm{Br}$, despite the $\operatorname{Br} \delta$ value remaining constant. To investigate these $S_{0}$ and $D_{50}$ behaviors, the relation for $S_{0}$ and $D_{50}$ versus $\mathrm{Br} \delta$ and $\mathrm{H}_{\mathrm{c}}$ were estimated.

Figure 3 shows that the dependence of $S_{0}$ on $\left(\mathrm{H}_{\mathrm{c}} \mathrm{Br} \delta\right)^{1 / 2}$ is strongly correlated. Since $\mathrm{Br} \delta$ is constant, the change in $\left(\mathrm{H}_{c} \mathrm{Br} \delta\right)^{1 / 2}$ is equivalent to that for $\mathrm{H}_{\mathrm{c}}^{1 / 2}$. Figure 4 shows that the dependence of $\mathrm{D}_{50}$ on $\left(\mathrm{H}_{\mathrm{d}} / \mathrm{Br} \delta\right)^{1 / 2}$ is also strongly correlated. Therefore, it was confirmed that the $S_{0}$ decline and $D_{50}$ decline in low $\mathrm{Br}$ media is due to the low $\mathrm{H}_{\mathrm{c}}$ value for the low $\mathrm{Br}$ media.

Table 1 Residual magnetic flux density (Br), film thickness $(\delta)$, coercivity $\left(\mathrm{H}_{c}\right)$, and coercivity squareness $\left(\mathrm{S}^{*}\right)$ of individual samples.

\begin{tabular}{|l|l|c|c|}
\hline $\mathrm{Br}(\mathrm{G})$ & $\mathrm{Hc}(\mathrm{Oe})$ & $S^{7}$ & $\delta(\mathrm{nm})$ \\
\hline 7,080 & 1,920 & 0.83 & 16 \\
\hline 5,090 & 1,810 & 0.79 & 22 \\
\hline 3,990 & 1,720 & 0.79 & 28 \\
\hline 2,970 & 1,510 & 0.72 & 37 \\
\hline 2,620 & 1,400 & 0.72 & 42 \\
\hline 2,280 & 1,220 & 0.72 & 48 \\
\hline 1,920 & 1,030 & 0.66 & 57 \\
\hline 1,580 & 820 & 0.49 & 70 \\
\hline
\end{tabular}

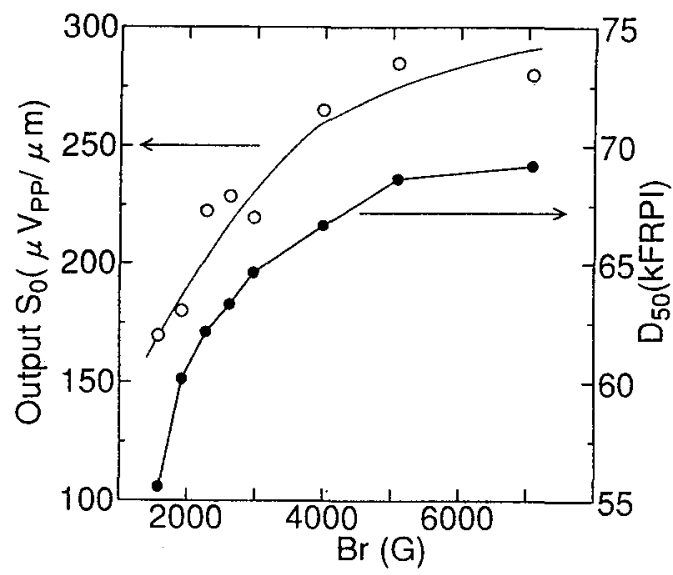

Figure 2 Dependence of isolated readback signal at $4 \mathrm{kFRPI}\left(\mathrm{S}_{0}\right)$ and recording density $\mathrm{D}_{50}$ on $\mathrm{Br}$ for the media samples (listed in Table 1).

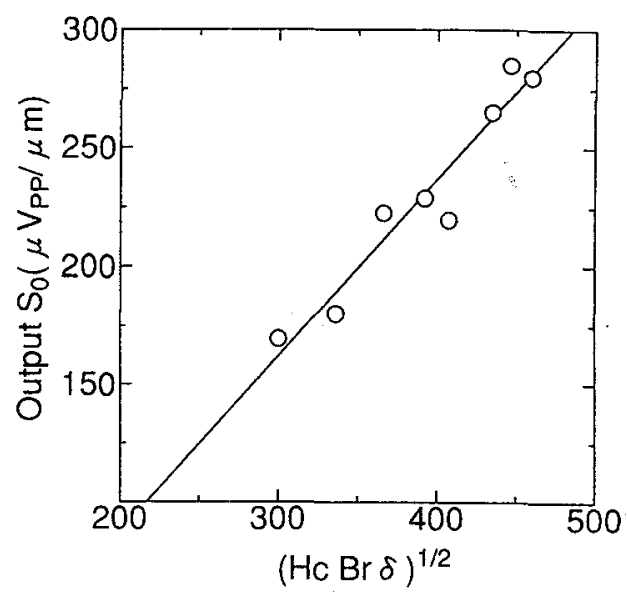

Figure 3 Dependence of isolated readback signal at $4 \mathrm{kFRPI}\left(\mathrm{S}_{0}\right)$ on $\left(\mathrm{H}_{\mathrm{c}} \mathrm{Br} \delta\right)^{12}$

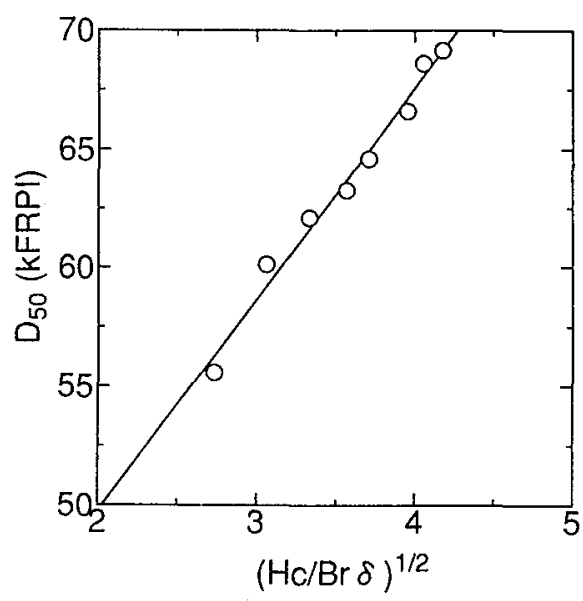

Figure 4 Dependence of $\mathrm{D}_{50}$ on $\left(\mathrm{H}_{\delta} / \mathrm{Br} \delta\right)^{1 / 2}$. 
Figure 5 shows the dependence of the integrated media noise and DC erase noise on Br. The signal density is $100 \mathrm{kFRPI}$. The media noise values were calculated by integrating the noise spectrum over $23.2 \mathrm{MHz}$ bandwidth, which corresponds to the 100 $\mathrm{kFRPI}$. The media noise decreases with a decrease in $\mathrm{Br}$. However, the $\mathrm{DC}$ erase noise difference between the low $\mathrm{Br}$ media and the high $\mathrm{Br}$ media is negligible. This result shows that the DC erase noise is independent from the $\mathrm{H}_{c}$ values.

Since the media samples, shown in Fig. 5, have different readback signal values, the media noises were normalized by the readback signal (S) at each linear density. Figure 6 shows the dependence of the media noise $(\mathrm{N})$ normalized by readback signal(S) on the recording density. The N/S values for all samples increase with an increase in recording density. The N/S curve slopes for the low $\mathrm{Br}$ media are much higher than those for the high $\mathrm{Br}$ media. From the longitudinal media noise to signal ratio view point, the high $\mathrm{Br}$ media with a thinner magnetic layer is preferable to the lower $\mathrm{Br}$ media with a thicker magnetic layer. However, if the $\mathrm{H}_{c}$ value for the low $\mathrm{Br}$ media is nearly equal to that for the high $\mathrm{Br}$ media, the readback signal and $S / N$ for the former would be larger. Therefore, $H_{c}$ improvement in the film preparation will be an important subject.

Figure 7 shows the dependence of the fluctuation in half-width of the readback waveform at $60 \mathrm{kFRPI}$ on Br. The half-width of readback waveform depends on the magnetic transition amplitude. The half width fluctuation is almost constant, between $3,000 \mathrm{G}$ and 7,000 G. However, the fluctuation value increases drastically below $\mathrm{Br} 2,000 \mathrm{G}$. This result shows that the fluctuation in the amplitude of the magnetic transition becomes large (below $\mathrm{Br}$ of $2,000 \mathrm{G}$ ).

Figure 8 shows the relationship between the N/S value and the half-width fluctuations of the readback waveforms at $60 \mathrm{kFRPI}$. The N/S values are strongly correlated to the half-width fluctuation. Therefore, it is concluded that the magnetic transition fluctuation for the lower $\mathrm{Br}$ media (below 2,000 G) is larger than that for the high $\mathrm{Br}$ media with less thickness. This result indicates that the $\mathrm{Co}-\mathrm{Cr}$ - $\mathrm{Ta}$ films microstructure degenerates for lower $\mathrm{Br}$ and thicker magnetic layers. $\mathrm{Cr}$ segregation states in high $\mathrm{Cr}$ content and grain size are cited as the degeneration factors.

\section{B. Noise characteristics of Co-Cr-Ta media and ferrite media}

Noise characteristics for ferrite media were investigated and compared them with those for $\mathrm{Co}-\mathrm{Cr}-\mathrm{Ta}$ media. The $\mathrm{H}_{c}$ values for as-deposited ferrite films are

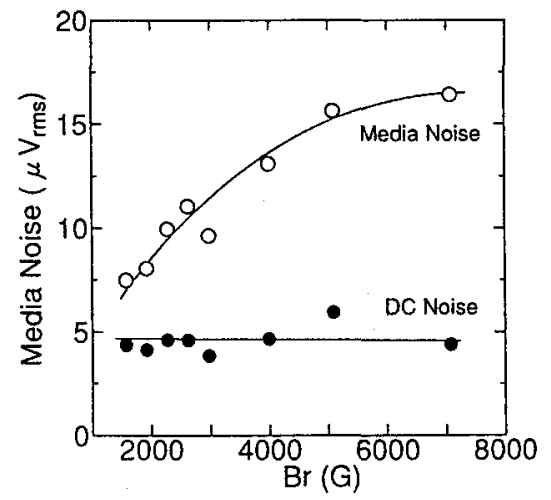

Figure 5 Dependence of integrated media noise and DC erase noise on $\mathrm{Br}$ for individual samples (listed in Table 1).

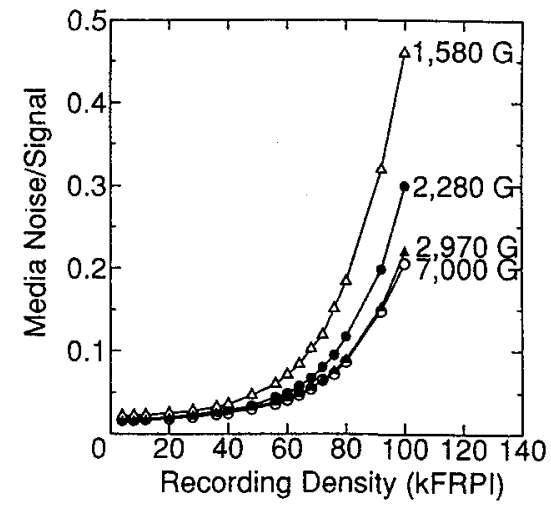

Figure 6 Dependence of media noise to signal ratio (N/S) on recording density for various $\mathrm{Br}$ media.

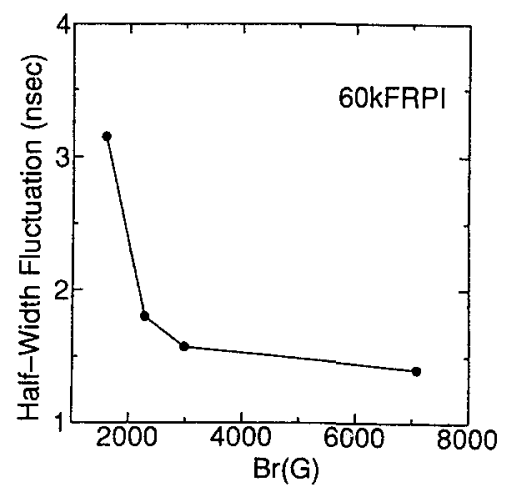

Figure 7 Dependence of the half-width fluctuation of readback waveform at $60 \mathrm{kFRPI}$ on $\mathrm{Br}$.

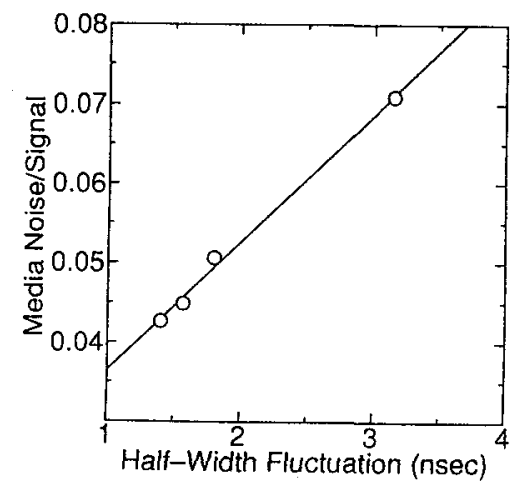

Figure 8 Correlation between N/S value and half-width fluctuation in the readback waveform at $60 \mathrm{kFRPI}$. 
several hundred Oe and those of annealed ferrite films becomes more than $1,000 \mathrm{Oe}$. $\mathrm{H}_{\mathrm{c}}$ increases with an increase in the annealing temperature. Ferrite film structures, which are independent of annealing temperatures, are spinel crystals with (111) preferred orientation. Ferrite media:A and ferrite media:B were annealed at $200^{\circ} \mathrm{C}$ and $400^{\circ} \mathrm{C}$ for 1 hour, respectively. The $\mathrm{H}_{c}$ values for ferrite media: $\mathrm{A}$ and ferrite media:B were $930 \mathrm{Oe}$ and $1360 \mathrm{Oe}$, respectively. The $\mathrm{Br}$ for the ferrite media with $50 \mathrm{~nm}$ thickness is about 2,200 G.

Figure 9 shows the dependence of the media noise $(\mathrm{N})$ to signal ratio at 4kFRPI $\left(\mathrm{S}_{0}\right)$ on recording density for ferrite media:A, ferrite media:B and $\mathrm{Co}-\mathrm{Cr}$ Ta media. The $\mathrm{H}_{c}$ value for Co-Cr-Ta media is 1,220 $\mathrm{Oe}$, which is nearly equal to that for ferrite media:B. Ferrite film media shows superior $\mathrm{N} / \mathrm{S}_{0}$ characteristics to Co-Cr-Ta film media. The $N / S_{0}$ value for ferrite media:A, annealed at $200^{\circ} \mathrm{C}$, is superior to that for ferrite media:B, annealed at $400^{\circ} \mathrm{C}$. Therefore, low annealing temperature is effective in decreasing in media noise. DC erase noise for the ferrite media is higher than that for the Co-Cr-Ta media. With an increase in recording density, the $\mathrm{N} / \mathrm{S}_{0}$ values for ferrite media are almost constant. On the other hand, the $\mathrm{N} / \mathrm{S}_{0}$ for $\mathrm{Co}$ $\mathrm{Cr}$-Ta media increases with increasing recording density. These different behaviors may come from the different noise power sources. Noise power for $\mathrm{Co}-\mathrm{Cr}-\mathrm{Ta}$ media mainly comes from the magnetic transition region. On the other hand, noise power for ferrite media as well as particulate media doesn't mainly come from the magnetic transition region. This is suggested by the difference in DC erase noises between ferrite media and Co-Cr-Ta media. Therefore, the ferrite media exhibits excellent potential for use as a low-noise media at high density recording.

Figure 10 shows $\delta \mathrm{M}$ plots versus the field normalized by the remanent coercivity. These plots depend on the isolation of the magnetic grains. These samples exhibit negative interaction between crystal grains. The magnetic grains isolation for ferrite media:A, annealed at a low temperature, is weaker than that for ferrite media:B annealed at a high temperature. Furthermore, this result shows that ferrite thin films also has static magnetic interactions between grains as do $\mathrm{Co}-\mathrm{Cr}-\mathrm{Ta}$ alloy film with $\mathrm{Cr}$ segregation.

\section{CONCLUSION}

The effect of residual magnetic flux density on the media noise for $\mathrm{Co}-\mathrm{Cr}-\mathrm{Ta}$ alloy thin films has been investigated. From the longitudinal media noise to signal ratio point view, the high $\mathrm{Br}$ media with a thinner magnetic layer is preferable to the lower $\mathrm{Br}$

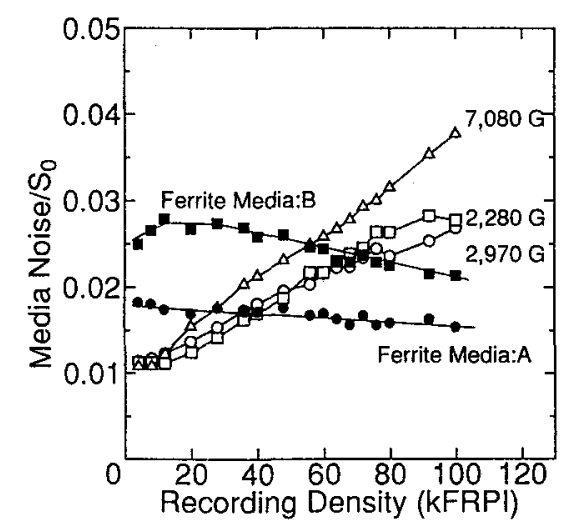

Figure 9 Dependence of the ratio for media noise $(\mathrm{N})$ to signal at $4 \mathrm{kFRPI}\left(\mathrm{S}_{0}\right)$ on recording density for ferrite media:A, ferrite media:B and $\mathrm{Co}-\mathrm{Cr}-\mathrm{Ta}$.

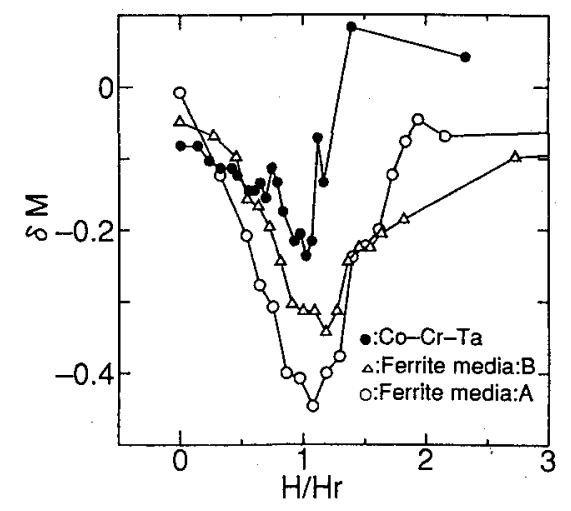

Figure $10 \delta \mathrm{M}$ plots versus the field normalized by the remanent coercivity for individual samples.

media (below 2,000 G) with a thicker magnetic layer. It was revealed that the media noise was proportional to the fluctuation in the magnetic transition region according to analysis of readback waveform. Furthermore, the ferrite media exhibits excellent potential for use as a low-noise media at high recording densities.

\section{ACKNOWLEDGEMENT}

The authors would like to thank Dr. H. Matsutera for useful discussions. The authors also would like to thank Mr. F. Suzuki and Mr. H. Hayashida for their help with sputtering and measuring the samples.

\section{REFERENCE}

[1] T. Korenari, H. Matsutera, S. Tsuboi and K.Tagami: J. Mag. Soc. Jpn., 17 Suppl.S2, pp109-113,1993.

[2] T. Korenari, S. Tsuboi, H. Matsutera and K.Tagami: Digests of the 18th Annual Conf. Magn. Jpn. 14pG-1,1994.

[3] K. Tagami, M. Aoyama, K. Nishimoto and F. Goto: IEEE Trans. Magn. Vol.MAG-21, No.2,pp1164-1169,1985.

[4] K. Tagami, K. Nishimoto and M. Aoyama : IEEE Trans. Magn. Vol.MAG-17, No.6,pp3199-3201, 1981.

[5] P. E. Kelly, K. O'Grady, P. I. Mayo and R. W. Chantrell : IEEE Tms. Magn., MAG-25, No.5, pp3881-3883,1989.

[6] J. G. Zhu and H. N. Bertram: IEEE Trans. Magn., MAG-24, pp2706-2708, 1988. 